\title{
Hydrogeochemistry and groundwater quality assessment of Astaneh-Kouchesfahan Plain, Northern Iran.
}

\begin{abstract}
In this study, the hydrochemical characteristics of 230 bore well samples were analysed in Astaneh-Kouchesfahan Plain. Data interpretation shows that alkaline earths $(\mathrm{Ca} 2+$ and $\mathrm{Mg} 2+)$ exceed the alkalis $(\mathrm{Na}+$ and $\mathrm{K}+)$ and weak acids $\left(\mathrm{HCO}^{-}\right)$exceed the strong acids $(\mathrm{Cl}-$ and SO42-) and Ca-HCO3 type is the dominant hydrochemical facies. The distribution patterns of the abundant parameters show that changes in chemical composition occurred in the middle, southwest and west of the area due to either natural geochemical process and/or anthropogenic activities. The results of factor analysis show that factor 1 of the pre-monsoon and factor 2 of the post-monsoon have high loading in the ions $\mathrm{Na}+$ and $\mathrm{Cl}-$. Furthermore, it is indicated that there is an increase in the loadings of $\mathrm{Ca} 2+, \mathrm{SO} 42-, \mathrm{HCO} 3-, \mathrm{Mg}_{2}+$ and $\mathrm{K}+$ in post-monsoon compared to pre-monsoon due to the effect of precipitation and subsequent dissolution of the calcareous rocks and fertiliser.
\end{abstract}

Keyword: Multivariate statistical analysis; Hydrogeology; Hydrochemistry; Groundwater pollution; R-mode factor analysis; Water quality; Water pollution; Groundwater quality; Iran; Hydrogeochemistry; Calcareous rocks; Fertiliser. 